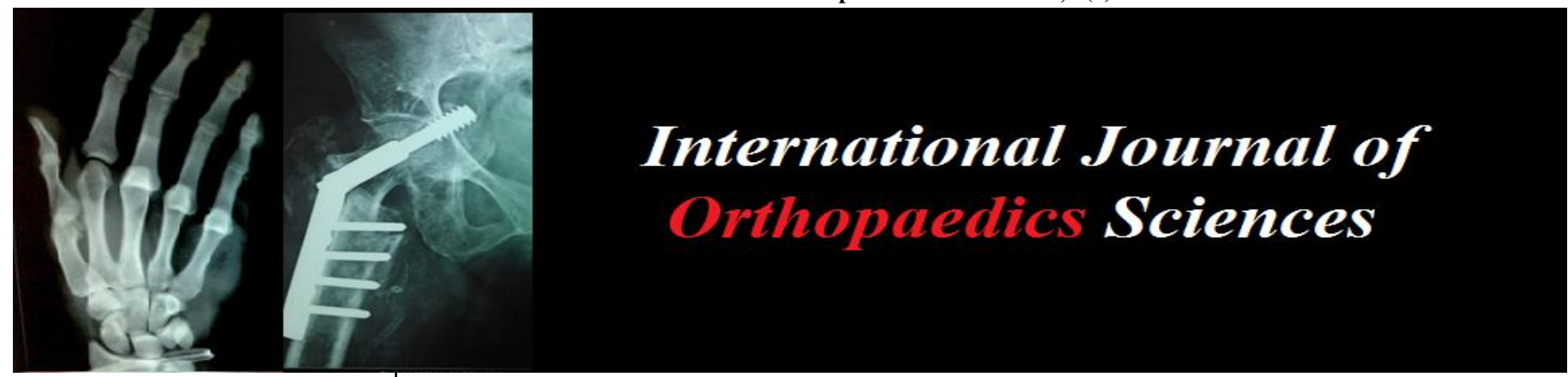

ISSN: $2395-1958$

IJOS 2018; 4(2): 558-560

(C) 2018 IJOS

www.orthopaper.com

Received: 14-02-2018

Accepted: 18-03-2018

Dr. Pradeep Kumar Saini

Senior Consultant,

Kasturba Hospital, Bhopal,

Madhya Pradesh, India

Dr. Sanat Singh

Associate Professor, GMC,

Vidisha, Madhya Pradesh, India

Dr. Ranjan Sinha

Senior Consultant,

Kasturba Hospital, Bhopal,

Madhya Pradesh, India
Correspondence

Dr. Pradeep Kumar Saini

Senior Consultant,

Kasturba Hospital, Bhopal,

Madhya Pradesh, India

\section{Result of tranexamic acid in controlling blood loss in total knee and hip replacement surgery}

\author{
Dr. Pradeep Kumar Saini, Dr. Sanat Singh and Dr. Ranjan Sinha
}

DOI: https://doi.org/10.22271/ortho.2018.v4.i2i.83

\section{Abstract}

Background: Blood loss is one of the major problems during intra-operative and postoperative periods after doing total knee and hip replacement. It is associated with high perioperative blood loss between 700 to $2,000 \mathrm{ml}$. High blood loss can lead to a longer hospital stay, impedes rehabilitation and may be poorly tolerated by patients with cardiovascular diseases (CVD).

Aims and Objective: To evaluate the effect of intravenously administered tranexamic acid (TXA) in controlling blood loss in total knee and hip replacement surgery.

Materials and Methods: Fifty patients undergoing total knee arthroplasty (TKA) and total hip arthroplasty (THA) were studied from April 2014 to March 2016 after dividing them into Group 1 (n=25; total hip replacement) and Group 2 ( $\mathrm{n}=25$; total knee replacement). All patients received TXA10 mg/kg 15 min before incision. As a primary outcome transfusion incidence, drain output, postoperative hemoglobin and hematocrit drop were evaluated. As a secondary outcome incidence of symptomatic deep vein thrombosis and pulmonary embolism within 30 days of surgery were evaluated.

Results: Female preponderance was noted $(60 \%)$. Pre operative hemoglobin was higher $(11.72 \mathrm{gm} \%)$ as compared to post operative hemoglobin at $2^{\text {nd }}(9.9 \mathrm{gm} \%)$ and $4^{\text {th }}$ day $(9.5 \mathrm{gm} \%)$ of surgery in Group 1 as well as in Group 2 pre operative hemoglobin was higher $(11.78 \mathrm{gm} \%)$ as compared to post operative hemoglobin at $2^{\text {nd }}(9.6 \mathrm{gm} \%)$ and $4^{\text {th }}$ day $(9.3 \mathrm{gm} \%)$. Drain $(\mathrm{ml})$ output in Group 1 and Group 2 was 150.2 and $170.4 \mathrm{ml}$ respectively. Blood transfusion was required only in one patient in Group 2.

Conclusion: TXA administered through intra venous route was found to decrease postoperative bleeding and requirement of transfusion in unilateral TKA and THR without increasing any risk of complications.

Keywords: Deep vein thrombosis, total knee arthroplasty, total hip arthroplasty, blood loss

\section{Introduction}

Blood loss during intra and post operative period is one of the major problems in patients undergoing total knee arthroplasty (replacement) (TKA) and total hip arthroplasty (THA). Reported perioperative blood loss during arthroplasty range from 700 to $2,000 \mathrm{ml}^{[1,2]}$.

High blood loss can result in to increased hospital stay, delay rehabilitation and may be poorly tolerated by patients with cardiovascular diseases. Because of that most of the patients require peri or postoperative blood transfusion ${ }^{[3]}$. Reports have shown that around $11-67 \%$ of the patients undergoing knee and hip arthroplasty require blood transfusion. This in turn increases the high economic costs of the procedure and risk of blood reaction and blood borne diseases. ${ }^{4}$ In order to present blood loss many techniques are used including autologous blood transfusion or autologous fibrin tissue application which have been used in clinical practice to reduce the postoperative blood transfusion rates ${ }^{[5]}$.

Though autologous transfusion reduces the risks of infection, but is also expensive. To minimize blood loss, hypotensive anesthesia is also used ${ }^{[6]}$. Another method for control of the perioperative blood loss is the application of antifibrinolitic agents including aprotinin, tranexamic acid (TXA) and epsilon-aminocaproic acid. Among them, TXA has attracted the most attention ${ }^{[7]}$.

Currently, in literature, there are numerous studies presenting the efficacy of TXA in reducing blood loss with no increase of complications. However, questions still remain about the type of administration, optimal dose and secondary outcomes of TXA in THA and TKA.

Hence in present study we tried to evaluate the effect of intravenously administered tranexamic acid (TXA) in controlling blood loss in total knee and hip replacement surgery. 


\section{Materials and Methods}

Present prospective randomized, single centre study was performed on 50 patients undergoing total knee and hip replacement and revision hip surgery from April 2014 to March 2016 at study place.

Patients having age between 55 to 85 years which may need total knee and hip replacement and revision hip surgery were included. Exclusion criterion included patient's history of venous or arterial thrombosis, acute renal failure, subarachnoid haemorrhage, allergies to TXA and seizure disorder.

Study cohort was divided into Group $1 \quad(n=25$; total hip replacement) and Group $2(\mathrm{n}=25$; total knee replacement). TXA was administered in dose of $10 \mathrm{mg} / \mathrm{kg} 15 \mathrm{~min}$ before incision.

\section{Intra-operative and postoperative management}

A standard postoperative protocol was followed in all patients. All patients had postoperative hematocrit and hemoglobin measurements on day 1 and 4. As hospital policy, the transfusion was given only at hemoglobin levels of $<8$ gm\%. The drains were emptied every day, and the amount of drained blood was measured. The drains were removed after 48 hours. Foleys catheter and compression bandage were removed on day 1 , and patients were encouraged for muscle strengthening exercises and walker assisted walking. Aggressive rehabilitation policy and inpatient physiotherapy were provided to all patients.

Chemical prophylaxis using low-molecular-weight heparin was given only in high-risk patients screened preoperatively. All patients were discharged after stitch removal.

\section{Outcome assessment}

The primary outcome variables were transfusion incidence, drain output, postoperative hemoglobin and hematocrit drop, calculated perioperative blood loss through gross formula ${ }^{8}$ and hemoglobin balance method ${ }^{[9]}$. The secondary outcome measurements were the incidence of symptomatic deep vein thrombosis (DVT) and pulmonary embolism within 30 days of surgery, duration of surgery, wound-related complications, including excessive oozing and skin ecchymosis and skin blisters.

All the data analysis was done using IBM SPSS (version 20.0; IBM, Chicago, IL, USA). Frequency distribution and cross tabulation was used to prepare table. The quantitative variables were expressed in terms of means \pm standard deviation. Analysis of variance and Tukey's post hoc were used for continuous outcome variables and Chi-square test for categorical outcome variables. Level of significance was assessed at $5 \%$

\section{Result}

Out of 50 patients, there were $30(60 \%)$ female and $20(40 \%)$ male. Blood transfusion was required only in one patient. No patients in any group developed symptomatic DVT or pulmonary embolism. No case of surgical site infection was noted in the study.

Table 1: Showing demography and outcome measurement in Group 1 ( $\mathrm{n}=25$; total hip replacement)

\begin{tabular}{|c|c|}
\hline Age (Years) & 70.16 \\
\hline Gender (male/female) & $11 / 14$ \\
\hline Preoperative hemoglobin $(\mathrm{gm} \%)$ & 11.72 \\
\hline Postoperative hemoglobin $(\mathrm{gm} \%)\left(2^{\text {nd }}\right.$ Day $)$ & 9.9 \\
\hline Postoperative hemoglobin $(\mathrm{gm} \%)\left(4^{\text {th }}\right.$ Day) & 9.5 \\
\hline
\end{tabular}

Table 2: Showing demography and outcome measurement in Group 2 ( $\mathrm{n}=25$; total knee replacement)

\begin{tabular}{|c|c|}
\hline Age (Years) & 66.96 \\
\hline Gender (male/female) & $9 / 16$ \\
\hline Preoperative hemoglobin $(\mathrm{gm} \%)$ & 11.78 \\
\hline Postoperative hemoglobin $(\mathrm{gm} \%)\left(2^{\text {nd }}\right.$ Day) & 9.6 \\
\hline Postoperative hemoglobin $(\mathrm{gm} \%)\left(4^{\text {th }}\right.$ Day) & 9.3 \\
\hline
\end{tabular}

Among one of them needs one unit blood transfusion post operatively.

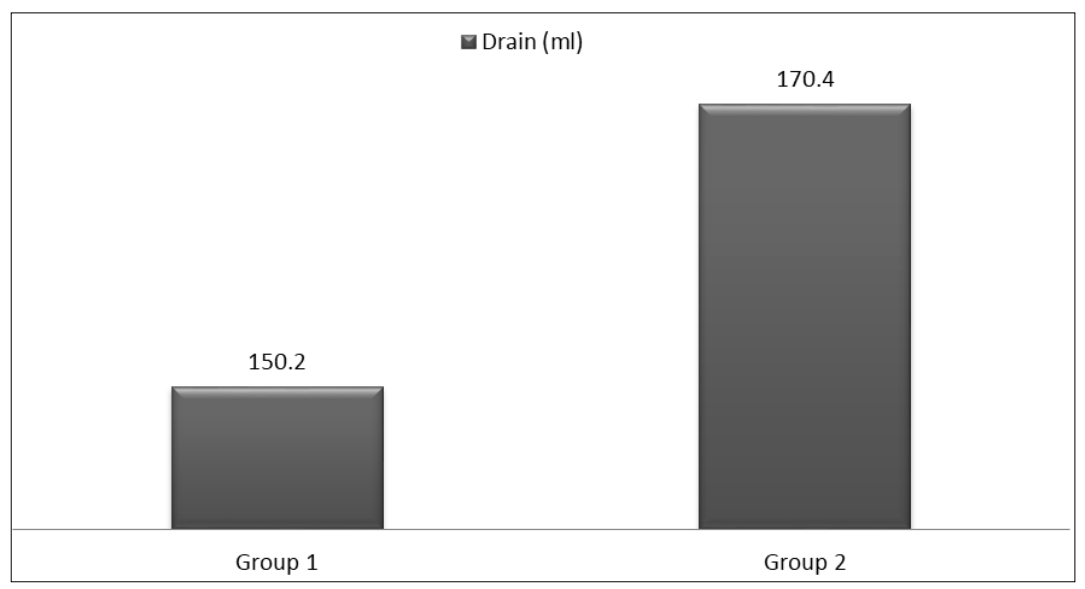

Graph 1: Showing Drain (ml) among study cohort

\section{Discussion}

Surgical trauma after arthroplasty results in a hyperfibrinolytic state. This is further augmented by increased fibrinolysis following tourniquet release ${ }^{[10]}$. Since early postoperative bleeding is the result of shift in hemostatic mechanism toward fibrinolysis, the antifibrinolytic drugs such as TXA are very effective to control this bleeding. Literature confirms this point, and there is little controversy regarding the effectiveness of drug ${ }^{[9,11]}$.
Similarly the present study has revealed that the combined group administration results in minimal bleeding following unilateral TKA and THR. IV administration of drug was found safe without any complications in any group due to drug administration.

IV administration of TXA is the most common route of administration in TKA and THA. TXA is distributed in the extracellular and intracellular spaces and reaches a high plasma concentration. Andersson et al. ${ }^{[12]}$ stated that after IV 
injection of $10 \mathrm{mg} / \mathrm{kg}$ of TXA, the plasma levels were highest within 1 hour. Thirty percentage of TXA was excreted in the urine after 1 hour, $55 \%$ at 3 hours and $90 \%$ after 24 hours. The half-life of TXA was reported to be between 80 minutes and 120 minutes. Moreover, 15 minutes after IV application, TXA reaches similar levels in the synovial fluid as in plasma [12]

The strength of $10 \mathrm{mg} / \mathrm{kg}$ has been shown to be effective in producing antifibrinolytic effect in various studies $[9,13,14]$. Drains in most series have been removed at fixed point of time i.e. 24-48 h, similarly in present study also we removed it after 48 hours ${ }^{[15-18]}$. Calculated losses were based on fixed day hemoglobin value in most series ( $2^{\text {nd }}$ or $4^{\text {th }}$ day). As concluded by most authors, we also found that the use of

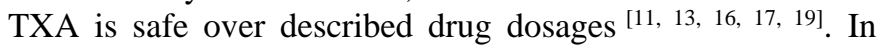
present study pre operative hemoglobin was higher as compared to post operative hemoglobin at $2^{\text {nd }}$ and $4^{\text {th }}$ day of surgery in Group 1 as well as in Group 2. Drain output in Group 1 was lower compared to Group 2. Owing to low incidence of DVT in Asian population, routine chemoprophylaxis is not warranted. No report of DVT was found in any group despite no use of routine prophylaxis. Only one patient required blood transfusion in present study. Similar to present study Oremus et al also reported that TXA use was associated with a decreased need for blood transfusions (odds ratio varying from $0.31-0.38$ by dose category) with no increased risk for complications ${ }^{[20]}$.

There are some limitations of this study. First, we also did not include patients who underwent simultaneous bilateral TKA in the present study, and therefore, our conclusions may not apply to these patients. Second, no blood studies have been carried out to estimate serum TXA levels following TKA and THR, and thus, no information regarding the toxicity related to TXA can be retrieved. Last, the present study has not addressed the subjective knee and hip function score of the patients after TKA and THR, as the main purpose of this study was to evaluate the blood transfusion after administration of drug.

\section{Conclusion}

IV administration of the TXA is most effective way to decrease postoperative bleeding and requirement of transfusion in unilateral TKA and THR without increasing any risk of complications.

\section{References}

1. Park JH, Rasouli MR, Mortazavi SM, Tokarski AT, Maltenfort MG, Parvizi J. Predictors of perioperative blood loss in total joint arthroplasty. J Bone Joint Surg Am. 2013; 95:1777-83.

2. Frisch NB, Wessell NM, Charters MA, Yu S, Jeffries JJ, Silverton CD. Predictors and complications of blood transfusion in total hip and knee arthroplasty. J Arthroplasty. 2014; 29(9):189-92.

3. Abrishami A, Chung F, Wong J. Topical application of antifibrinolytic drugs for on-pump cardiac surgery: a systematic review and meta-analysis. Can J Anaesth. 2009; 56:202-12.

4. Good L, Peterson E, Lisander B. Tranexamic acid decreases external blood loss but not hidden blood loss in total knee replacement. Br J Anaesth. 2003; 90:596-9.

5. Mawatari M, Higo $T$, Tsutsumi $Y$, Shigematsu $M$, Hotokebuchi T. Effectiveness of autologous fibrin tissue adhesive in reducing postoperative blood loss during total hip arthroplasty: a prospective randomised study of 100 cases. J OrthopSurg (Hong Kong). 2006; 14:117-121.

6. Conteduca F, Massai F, Iorio R, Zanzotto E, Luzon D, Ferretti A. Blood loss in computer-assisted mobile bearing total knee arthroplasty. A comparison of computer-assisted surgery with a conventional technique. IntOrthop. 2009; 33:1609-1613.

7. Keyhani S, Esmailiejah AA, Abbasian MR, Safdari F. Which route of tranexamic acid administration is more effective to reduce blood loss following total knee arthroplasty? Arch Bone Jt Surg. 2016; 4:65-69.

8. Gross JB. Estimating allowable blood loss: Corrected for dilution. Anesthesiology. 1983; 58:277-80.

9. Chen JY, Chin PL, Moo IH, Pang HN, Tay DK, Chia SL et al. Intravenous versus intra-articular tranexamic acid in total knee arthroplasty: A double-blinded randomised controlled noninferiority trial. Knee. 2016; 23:152-6.

10. Rajesparan K, Biant LC, Ahmad M, Field RE. The effect of an intravenous bolus of tranexamic acid on blood loss in total hip replacement. J Bone Joint Surg Br. 2009; 91:776-83.

11. Alshryda S, Sukeik M, Sarda P, Blenkinsopp J, Haddad FS, Mason JM. A systematic review and meta-analysis of the topical administration of tranexamic acid in total hip and knee replacement. Bone Joint J. 2014; 96-B:1005-15.

12. Andersson L, Nilsson IM, Niléhn JE, Hedner U, Granstrand B, Melander B. Experimental and clinical studies on AMCA, the antifibrinolytically active isomer of p-aminomethyl cyclohexane carboxylic acid. Scand J Haematol. 1965; 2:230-247.

13. Abul-Azm A, Abdullah KM. Effect of topical tranexamic acid in open heart surgery. Eur J Anaesthesiol. 2006; 23:380-4.

14. Baric D, Biocina B, Unic D, Sutlic Z, Rudez I, Vrca VB et al. Topical use of antifibrinolytic agents reduces postoperative bleeding: A double-blind, prospective, randomized study. Eur J Cardiothorac Surg. 2007; 31:366-71.

15. Gomez-Barrena E, Ortega-Andreu M, Padilla-Eguiluz NG, Pérez-Chrzanowska H, Figueredo-Zalve R. Topical intra-articular compared with intravenous tranexamic acid to reduce blood loss in primary total knee replacement: A double-blind, randomized, controlled, no inferiority clinical trial. J Bone Joint Surg Am. 2014; 96:1937-44.

16. Patel JN, Spanyer JM, Smith LS, Huang J, Yakkanti MR, Malkani AL. Comparison of intravenous versus topical tranexamic acid in total knee arthroplasty: A prospective randomized study. J Arthroplasty. 2014; 29:1528-31.

17. Hamlin BR, DiGioia AM, Plakseychuk AY, Levison TJ. Topical versus intravenous tranexamic acid in total knee arthroplasty. J Arthroplasty. 2015; 30:384-6.

18. Jain NP, Nisthane PP, Shah NA. Combined administration of systemic and topical tranexamic acid for total knee arthroplasty: Can it be a better regimen and yet safe? A randomized controlled trial. J Arthroplasty. 2016; 31:542-7.

19. Seo JG, Moon YW, Park SH, Kim SM, Ko KR. The comparative efficacies of intra-articular and IV tranexamic acid for reducing blood loss during total knee arthroplasty. Knee Surg Sports Traumatol Arthrosc. 2013; 21:1869-74.

20. Oremus K. Tranexamic acid for the reduction of blood loss in total knee arthroplasty. Ann Transl Med. 2015; 3(1):S40. 